\title{
Sistema Faxinal: uma forma de organização camponesa em desagregação no Centro-sul do Paraná
}

\begin{abstract}
CHANG, Man Yu. Sistema Faxinal: uma forma de organização camponesa em desagregação no Centro-sul do Paraná. Londrina: IAPAR, 1988. 124p.
\end{abstract}

Marcelo Barreto

Universidade de São Paulo

Na presente obra, a autora Man Yu Chang busca compreender as reconfigurações no campesinato diante do processo de avanço das forças capitalistas no campo, o que vem ocorrendo na região Centro-sul do Paraná principalmente desde a década de 1960. Ao pesquisar os faxinais, Man Yu Chang procura trazer em evidência o caráter específico dessa "forma de organização camponesa" que é a pratica do uso comum de terras.

Publicado na década de 1980, este trabalho figura como um dos pioneiros sobre o assunto dos faxinais e se constitui como referência para as pesquisas que vêm sendo realizadas sobre estes camponeses.

A autora entende que o capitalismo, ao avançar no campo, provoca a dissolução da forma tradicional da organização camponesa dos faxinais, que é o uso comum de suas terras, conhecido como criadouro comunitário. Neste sentido, seu maior esforço está em identificar as causas que levam estes sujeitos a abandonarem a organização em torno dos criadouros comunitários e a praticarem uma agricultura pautada pelos parâmetros da modernidade: tecnificada e integrada cada vez mais à produção industrial, enquanto estratégia de sobrevivência de suas famílias.

Na busca da acumulação ampliada, o capital avança no campo procurando abrir novas frentes para expandir-se. Diante desse processo, em que as forças capitalistas avançam no campo, os camponeses buscam redefinir novas estratégias para se reproduzirem socialmente em um movimento contínuo de garantia da sobrevivência de suas sociedades. Estas estratégias os levam, muitas vezes, a reconfigurarem a sua produção em meio à diversidade de situações provocadas, tanto pelo enfrentamento quanto pela sujeição aos interesses do capital.

Neste sentido, a autora parte da hipótese de que existe um processo em curso que pode provocar a dissolução dos criadouros comunitários levando, assim, à desagregação dos faxinais - processo este causado pelo avanço da agricultura moderna na região Centro-sul do Paraná, o que se intensificou na década de 1970. A pesquisa de Man Yu Chang está ligada ao programa de desenvolvimento rural integrado (PRORURAL), que foi realizado entre os anos de 1982 e 1984, no qual havia a necessidade de se abordar, juntamente com as questões técnicas, os problemas de ordem econômica e social no que tange às formas de organização camponesa no Paraná.

O trabalho desenvolve-se tendo como base a racionalização de um sistema produtivo ligado à atividade econômica que se constituía como fator de desenvolvimento da região no final do século XIX ${ }^{1}$. No entanto, esta racionalidade acabou se transformando em uma irracionalidade

${ }^{1}$ Essa atividade era representada pela extração e beneficiamento da erva-mate. 
no momento em que se alteraram as bases econômicas da região na qual os faxinais vêm se reproduzindo, transformação essa marcada por um movimento de superação de uma forma de produção tida como tradicional para outra mais moderna, integrada cada vez mais à lógica capitalista.

Para Chang, a formação dos faxinais se deu associada a dois fatores principais: um relacionado ao quadro de condicionantes físico-naturais e outro a um conjunto de fatores econômicos favoráveis que se constituiu no fim do século XIX². Assim, os faxinais acabaram se desenvolvendo nas seguintes atividades: produção animal para consumo próprio, produção agrícola para comercialização e consumo próprio e extração da erva-mate como renda complementar.

Evidencia-se no trabalho de Chang a permanência de condições que são menos expressivas no mundo atual e que traz consigo um elemento de grande persistência, representado pela reprodução das condições de produção contraditória ao atual momento do desenvolvimento capitalista na agricultura (a presença do criadouro comunitário). Isso aparece na obra marcada pela polaridade capitalista/ não capitalista. Na hipótese inicial da obra, além da afirmação de que os faxinais estão se desagregando, evidencia-se também que esta desagregação conduz a profundas implicações sociais no contexto regional. Neste sentido, faz-se necessário conhecer as causas dessa desagregação, o que leva ao questionamento sobre a razão da permanência dos faxinais na atualidade.

Existe uma preocupação da autora em passar para o público leitor que as propostas alternativas de intervenção para esses

${ }^{2}$ Com as fortes demandas dos mercados argentino, chileno e uruguaio, o estado do Paraná se tornou o maior exportador de erva-mate do mundo no final do século XIX. Este fato tornou possível a formação de uma burguesia ervateira na cidade de Curitiba, ligada principalmente à atividade de beneficiamento da erva-mate (PEREIRA, 1997). camponeses devem se pautar na realidade social. Neste sentido, busca-se conhecer as formas como a produção está organizada e quais os processos em curso que envolvem esses sujeitos. Chang procura, então, conhecer as especificidades dos faxinais identificando as transformações que acontecem nas comunidades; como e em que condições histórico-econômicas os faxinais se formaram e as condições atuais do avanço do capitalismo no campo que levam à sua desagregação.

A gênese dos faxinais aparece como derivada de dois elementos: primeiro, a partir da estrutura de subsistência das grandes fazendas e, segundo, os costumes - ambos ligados às condições naturais das regiões Centro-sul e Sudeste do Paraná. A partir da crise dos latifúndios monocultores, que se encontravam nas regiões campestres do Paraná no século XIX, e do movimento migratório para as regiões das florestas, as comunidades que já se encontravam nestes locais (florestas) passaram a receber grande contingente demográfico proveniente das fazendas de criação e invernada localizadas, principalmente, nos Campos Gerais.

Os termos racionalidade e modo de vida aparecem na obra como semelhantes. A racionalidade econômica é tida como um conceito histórico. Construído a partir das condições econômicas da época. Já o modo de vida acaba sendo resultante da constante busca de um equilíbrio racional entre o dispêndio de trabalho e os recursos naturais à disposição.

O modo de vida dos caboclos que se encontravam na Floresta com Araucária antes da migração européia do final do século XIX e início do $X X$ foi superado e deu origem a outra forma de organização, devido ao aumento demográfico nestas regiões e ao desenvolvimento econômico e social. Esta outra forma de organização ficou conhecida como faxinais. 
O contato com os imigrantes europeus, que foram alocados na floresta por meio das políticas de colonização promovidas pelos governos: federal e da província do Paraná e que trouxeram novas técnicas de agricultura levou a profundas modificações no modo de vida dos caboclos, existente na região. No entanto, estes mesmos imigrantes acabaram tendo que se adaptar à organização cabocla, baseada na criação de animais à solta, devido às condições naturais da região.

Com este aumento da população, houve uma inversão da forma de cercamento: as lavouras, que antes ocupavam a mesma área de criação e eram cercadas para conter o avanço dos animais, se deslocaram para outras áreas (as terras de plantar) e os animais passaram a ser mantidos em terrenos contíguos. As áreas, antes abertas, passaram a ser demarcadas devido às constantes situações de conflito com os imigrantes, principalmente os poloneses. Derivava daí a necessidade de se criarem leis municipais que passassem a regular os criadouros comunitários ${ }^{3}$.

A economia ervateira aparece como o motor indutor da formação dos faxinais. A passagem, que se deu da organização cabocla para os faxinais propriamente ditos, não aconteceu sem conflito, principalmente entre as diferentes classes que se constituíram. A autora identifica a formação de diferentes categorias sociais com a atividade ervateira na região. São elas: os simples colhedores que não possuem terras, os pequenos proprietários e os grandes proprietários. Essas categorias sociais derivavam das diferentes formas de inserção na economia ervateira, cuja diferença era determinada pela propriedade privada da terra e a renda que a mesma proporcionava.

${ }^{3}$ Contrapondo-se à ideia de Man Yu Chang de que o criadouro comunitário aparece enquanto racionalidade, os autores Tavares (2008) e Nerone (2000) entendem que o criadouro comunitário dos faxinais possui múltiplas origens que remetem à agricultura tanto praticada pelos imigrantes na sua terra de origem, quanto a desenvolvida pelos índios e negros fugidos das fazendas do período coloniais.
A não contratação de trabalhadores permanentes nas grandes propriedades se justificava pela sazonalidade no corte da erva-mate. Entretanto, estes proprietários, que possuíam grandes extensões de terras dentro dos faxinais, necessitavam que uma grande quantidade de camponeses permanecesse junto a eles para trabalhar com outras culturas no período da entressafra da erva-mate. Consolidaram, assim, nos criadouros comunitários dos faxinais, relações que eram permeadas pelas formas de renda pré-capitalista da terra (rendas em trabalho, dinheiro e produto). Os camponeses que não possuíam terras permaneciam na condição de agregados e, ao mesmo tempo, podiam criar seus animais livremente nos criadouros comunitários. Essas relações, apresentadas por Chang em seu trabalho, acontecem no interior dos faxinais entre camponeses de distintas categorias sociais.

Com a intensificação cada vez maior do modo de produção capitalista no campo dos faxinais, esses sujeitos acabaram passando pelo processo de diferenciação. Este processo levou ao surgimento de dois circuitos econômicos na região: o das unidades familiares de subsistência e o das empresas especializadas na exploração ${ }^{4}$.

Chang imprime uma ideia de movimento em seu trabalho para demonstrar que os faxinais se consolidaram conforme uma racionalidade que se apresenta vulnerável ao desenvolvimento global das forças econômicas. A autora procura captar esse movimento em que o campo vai se modernizando por meio da aliança

\footnotetext{
${ }^{4} \mathrm{O}$ conceito de diferenciação é trabalhado por autores que procuram compreender o campesinato no modo capitalista de produção. Trabalhos clássicos como os de Karl Kautsky (1980) e Maurice Dobb (1981) orientaram a concepção teórica adotada por autores como Ricardo Abramovay(1998) e Man Yu Chang (1988). Tal concepção se baseia na tese de que o modo capitalista de produção, ao avançar no campo, provoca a modernização do mesmo; o que leva os camponeses a se tornarem micro empresários, integrados à indústria ou, ao empobrecimento dos mesmos e, posteriormente, à proletarização nas grandes cidades.
} 
entre a grande propriedade e a burguesia industrial - é uma modernização do campo que acaba sendo discriminadora devido à concentrada estrutura fundiária do campo brasileiro. A diferenciação entre os produtores familiares é causada por essa modernização, a qual levou à cisão entre os que se capitalizaram e os que acabaram ficando marginalizados do processo produtivo. Há uma polaridade que a autora identifica marcada pela tecnificação x marginalização.

Dentro do debate sobre a "perpetuação" ou "eliminação" da produção camponesa, é consenso geral que a produção agrícola, tanto a produção familiar quanto a grande empresa rural, segue uma tendência crescente de intensificação da produção (maior aplicação de trabalho por área, principalmente o morto). A intensificação faz alterar, no caso da produção familiar, a natureza da produção familiar, que é o que se está interessado. O mínimo de terra e de condições materiais necessárias para a reprodução de uma família camponesa altera-se com o desenvolvimento histórico das forças produtivas no campo. E a obtenção dessas condições materiais de produção torna-se um verdadeiro fator de diferenciação social, particularmente a horizontal (p. 72).

Seguindo este raciocínio, Chang constatou que existe um processo geral de desagregação dos criadouros comunitários nos faxinais. É um processo gradual que acontece por duas vias: uma pelo abandono da criação de animais à solta e outro pela diminuição do criadouro provocado pela venda de terrenos dentro do criadouro para empresas rurais ligadas ao agronegócio. Isso acabou levando ao desaparecimento do criadouro comum e ao cercamento da propriedade individual.

O movimento de superação de uma forma tradicional para outra mais "mo- derna", dentro da lógica capitalista, aparece atrelado ao movimento global do capitalismo. Se, em um momento da história, os criadouros comunitários eram vantajosos do ponto de vista da racionalidade econômica, em outro momento, os mesmos deixaram de ser. Neste sentido, a autora analisa alguns fatores nos quais se processa essa desintegração. São eles: a questão técnica, o papel do Estado, o aumento da produção agrícola, esgotamento dos recursos naturais, a questão da terra e o embate entre as leis federais as leis municipais.

Na região Centro-sul do Paraná, após a década de 1960, a modernização da agricultura provocou uma inversão da racionalidade econômica preexistente. Houve uma demanda por parte da economia camponesa, no sentido técnico de racionalização da produção devido à interferência de agentes externos. Um exemplo é quanto à criação de animais: enquanto a floresta nativa e a abundância de terras garantiam fonte de alimento para estes, não havia necessidade de se adquirir ração fora dos limites do criadouro. A supressão desses recursos naturais (terra e floresta) levou os faxinalenses a adquirir o alimento da criação fora de suas terras, criando assim uma situação de dependência cada vez maior das técnicas e insumos produzidos pela indústria capitalista.

Os faxinais se configuraram em meio às estratégias de reprodução social dos pequenos agricultores em conjunto com os interesses dos grandes proprietários. Embora haja um movimento de forças que atuam no sentido da desagregação do modo de vida dos faxinalenses, estes sujeitos vêm resistindo a esse processo de ruptura por meio da luta pela permanência na terra e pela proteção dos seus costumes. Este novo elemento (luta pela permanência na terra) vem ganhando força entre as comunidades de faxinais e se constitui como uma possibilidade 
de reprodução social desses sujeitos na atualidade.

\section{REFERÊNCIAS}

ABRAMOVAY, R. Padigmas do Capitalismo Agrário em Questão. 2 .ed. São Paulo: Hucitec, Campinas: EDUNICAMP, 1998. 275p.

DOBB, M. A Evolução do Capitalismo. Trad. Manuel do Rego Braga. 8 ed. Rio de Janeiro: Zahar, 1981. 396p.

KAUTSKY, K. A Questão Agrária. Trad. Moniz Bandeira. 3 ed. São Paulo: Proposta, 1980. 329p.

NERONE, M. M. Terras de Plantar, Terras de Criar - Sistema Faxinal - Rebouças - 1950 - 1997. 2000, 286p. (Tese de Doutorado), UNESP, Assis, 2000.
PEREIRA, M. R. M. Dos Usos e Abusos do Mate: sociedade e indústria no Paraná do século XIX. In: Cativeiro e Liberdade (Revista Interdisciplinar de História Social), Rio de Janeiro, jan./jun., 1997, pp. 69-103.

TAVARES, L. A. Campesinato e os Faxinais do Paraná: as terras de uso comum.2009, 755p. (Tese de doutorado), USP, São Paulo, 2008.

Recebido em: 28/09/11 Aceito em: 05/11/11 